\title{
Sport and ageing: a systematic review of the determinants and trends of participation in sport for older adults
}

\author{
Claire R. Jenkin ${ }^{*^{*}}$ D, Rochelle M. Eime ${ }^{1,2}$, Hans Westerbeek', Grant O'Sullivan ${ }^{1}$ and Jannique G. Z. van Uffelen ${ }^{1,3}$
}

\begin{abstract}
Background: The global population is ageing. As ageing is often associated with a decline in health, there is a need to further develop preventative health measures. Physical activity can positively influence older adults' (aged 50 years and older) health. Previous research on the relationship between physical activity and health for older adults has mainly focused on physical activity in general, and not specific types of exercise. Due to the social nature of sport, it may assist in improving physical, mental and social health for older adults. Sport, as a form of physical activity, has not been widely explored as a physical activity opportunity for older adults. This review concurrently explored two research questions: the determinants and the trends of sport participation for community dwelling older adults.
\end{abstract}

Methods: Two parallel systematic searches of nine electronic databases were conducted in December 2015 for the two research questions. English language quantitative and qualitative studies that provided specific results for community dwelling older adults' sport participation were included and a quality ratings assessment was undertaken.

Results: There were 10,171 studies initially identified for the first research question and 1992 studies for the second research question. This culminated in 18 and 8 studies respectively that met the inclusion criteria. The most frequently mentioned determinants of participation were health and using sport to negotiate the ageing process. The most frequently mentioned trends of sport participation were the effect of historical sport participation on current participation, and sport participation across the lifespan. The main themes for both research questions had contrasting results, for example, participation in sport could improve health, but poor health was also a limitation of sport participation.

Conclusions: This review demonstrates that older adults are a heterogeneous age group, and therefore require different strategies than other age groups to successfully participate in sport. It is recommended that the main findings from this review are incorporated into specific strategies to develop age appropriate sporting opportunities for older adults, so that sport can be presented as a viable physical activity option for this age group.

Keywords: Older adults, Sport participation, Determinants, Trends

\section{Background}

Populations throughout the world are ageing, and the amount of people aged over 65 years is shortly expected to outnumber children under five years old [1]. As people age, they are more likely to suffer from ill health, including chronic disease [2]. Physical inactivity is a significant contributor to the development of chronic

\footnotetext{
* Correspondence: clairejenkin@hotmail.com

'Institute of Sport, Exercise and Active Living (ISEAL),Victoria University,

Melbourne, VIC 8001, Australia

Full list of author information is available at the end of the article
}

diseases [3], therefore regular physical activity is important for older adults' health and quality of life.

The health benefits of physical activity, specifically for older adults, have been comprehensively researched. For older adults, physical activity can be beneficial for physical [4], mental [5] and social [6] health. Besides the health benefits of regular participation, other aspects of participation among older adults have also been reviewed. Previous systematic reviews on physical activity in this population group have for example focused on: the physical health risks involved in participation [7], the differences between determinants of physical activity and exercise [8], whether 
older adults are meeting the recommended physical activity participation levels [9], the health benefits [10], strong social networks [11] and the effect of physical activity in alleviating depression in older adults [12]. Although the health benefits of generic physical activity have been extensively researched for older adults, there is little research on sport as a form of leisure-time physical activity for this population group. This limited research has largely focused on Masters/Senior Games sport participation [13-19] or on specific sports, such as bowls [20], golf [21], curling [22] or lifeball [23] rather than general community sport. As the determinants of participation may vary for different forms of exercise [24], specific research for older adults and general community sport participation is required. In this review, community sport is defined as "a human activity capable of achieving a result requiring physical exertion and/or physical skill which, by its nature and organisation, is competitive and is generally accepted as being a sport" [25].

Deriving benefits of physical activity can influence continuation of participation. In sport, there have been a number of systematic reviews examining the concept of sport being beneficial for health for younger age groups, [26-28] but not specifically for older adults, who may have different health outcomes. Therefore, with the expected declining health of an ageing population, it is important to investigate the determinants of initiating and continuing sport participation for older adults, to diversify the physical activity options available to this age group.

It is noteworthy that a recent narrative literature review [29] identified that whilst there can be numerous psychosocial benefits for some older adults who play sport, sport is a multi-faceted concept and as such, the socio-cultural contexts of older adults' participation in sport needs to be considered. This current systematic review aims to build on the knowledge collated from this narrative review [29] in several ways. Firstly, to broaden the scope to review studies that also examine older adults' participation in community-based sport clubs, as the majority of the literature in this narrative review related to large scale competitive events, like the Masters Games. Secondly, to look beyond solely subjective meaning found in participation to any influence that may determine sport involvement, such as demographics and also overall trends in participation.

Sport, as a type of leisure-time physical activity, is receiving increasing academic interest in ageing research [29-31]. Sport is often undertaken at community sport clubs in Australia [32, 33], and given the social nature of club-based sport, engaging older adults in sport may positively contribute to their physical, mental and social health. However, few older adults participate regularly in organised sport [34], therefore a review of the literature specific to older adults' community sport participation is needed to identify potential determinants and trends of their participation.
This systematic review had two research questions: 'What are the determinants of sport participation for community dwelling older adults?' and 'What are the trends of sport participation for community dwelling older adults?' The decision to include both of these research areas in this review was based on the premise that determinants can influence patterns of sport participation either positively or negatively over the lifespan.

\section{Methods}

\section{Search strategy}

The two research questions led to two literature searches that were conducted in parallel, to identify research articles meeting the inclusion criteria for each of these questions.

Seven categories of determinants (biological, psychological, behavioural, physical, socio-cultural, socioeconomic and policy) [35] that can influence participation or non-participation have been previously identified and were used in the inclusion criteria. The term 'trends of participation' was not specifically defined in the reviewed articles, so for the purpose of this review, trends were defined as participation levels or lifecourse participation. As Eime, Sawyer, Harvey, Casey, Westerbeek and Payne [36] state, the measure of sport participation trends is important for a range of sectors including sport, recreation and health. Other studies [37] have also investigated the determinants of participation in sport, but not for older adults.

The search terms for first research question were: [Sport" OR "sport" participation"] AND [Adult" OR "older adult*] AND [Determinant* OR reason* OR benefit* OR barrier* OR value]. For the second research question, the search terms were: Sport* OR "sport" participation" AND Adult* OR "older adult* AND Trend* OR lifecourse. The truncation symbol $\left({ }^{*}\right)$ was used to ensure all relevant uses of these search terms were included in the search.

Full database searches were conducted on 17th December 2015 across nine electronic databases: PubMed, Scopus, Cochrane, Cumulative Index to Nursing and Allied Health Literature (Cinahl), SPORTDiscus, AusSportMed, EBSCHOHost (including Health Business Elite, Health Source-Consumer Edition, Humanities International Complete, MEDLINE with full text, PsycARTICLES and PsycINFO, Informit), Psychology and Behavioural Sciences, and Health Collection. The searches were also limited to full English language peer reviewed articles.

\section{Selection criteria}

In line with other recent research in older adults and sport [31], articles were included if there was specific data on sport participation in community dwelling adults aged 50 years or older (classified as older adults in this study). Sport participation was defined using the Australian Sports Commission's definition [25]. Included studies also had to be restricted to older community- 
dwelling adults (for example, not in institutions such as hospitals). Furthermore, included studies were those that were empirically based (quantitative or qualitative) and published in peer reviewed journals. Articles were excluded if they were specific clinical or disability population studies and/or impairment or injury studies. If studies presented clear sport results in the abstract, they were included. However, as sport can be often defined in different ways and can be included as a type of physical activity or exercise, studies where it was unclear if there were specific sport results at the abstract stage were escalated to the full paper stage for review.

\section{Search process}

The titles of studies were screened by one researcher. Abstracts were then screened by two researchers to ensure they met the inclusion criteria. The next stage involved two researchers screening the full text of articles to determine if they met the inclusion criteria. The reference lists of included full-text articles were then checked for additional relevant articles, which were also screened by two researchers for inclusion. Disagreements with regards to the inclusion of articles were discussed and resolved between these two researchers. See Figs. 1 and 2 for full details of this process.

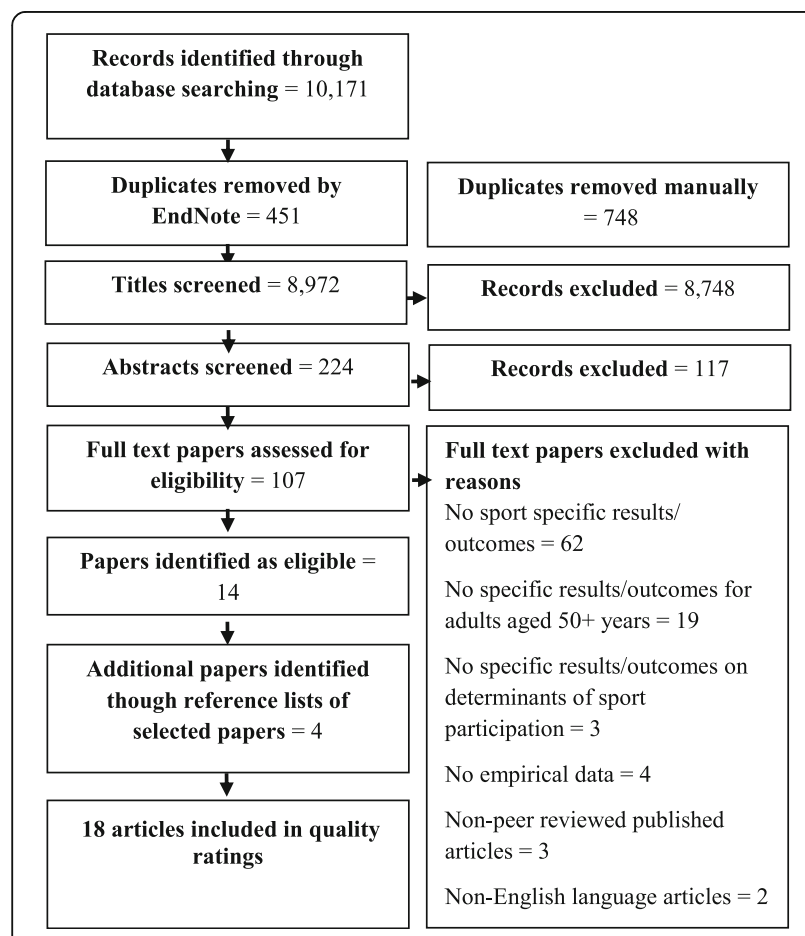

Fig. 1 Search process What are the determinants of sport participation for community dwelling older adults?

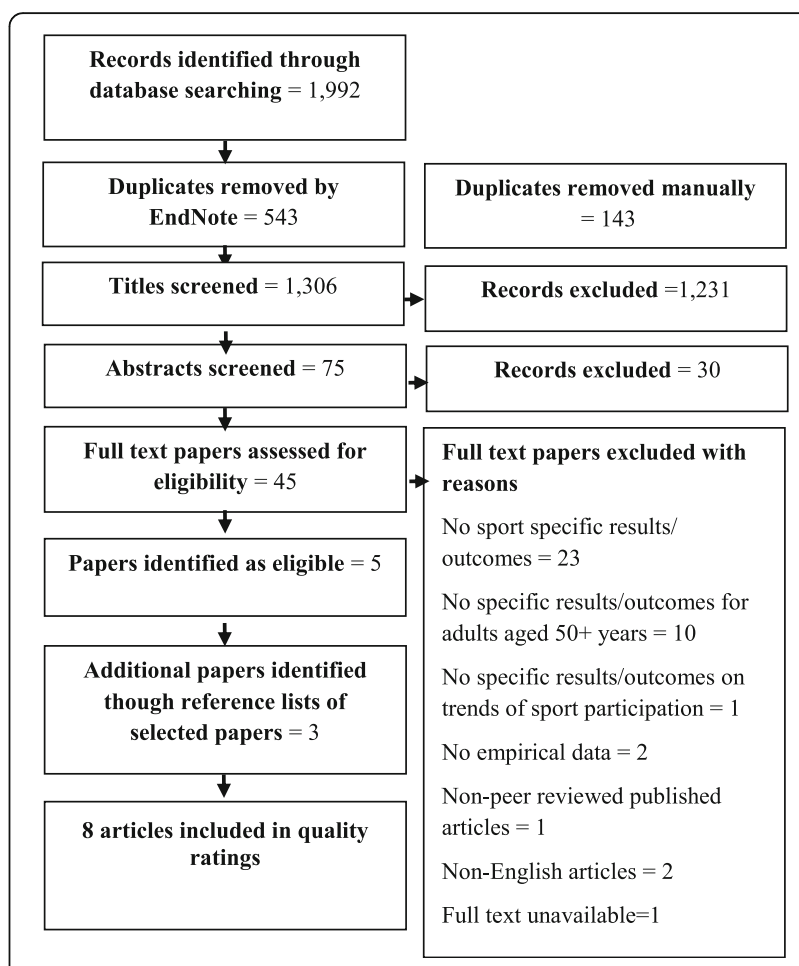

Fig. 2 Search process: What are the trends of sport participation for community dwelling older adults?

\section{Study analysis}

Once included, the articles were analysed thematically to report the main findings from each article that were relevant to the research question.

\section{Quality rating}

The quality rating list developed by Kmet, Lee and Cook [38] was selected for the quality rating process, as it suitable for both quantitative and qualitative studies. This list has been cited extensively and used in numerous mixed methods systematic reviews [39-41].

The quality ratings system [38] involved 14 quality assessment items for quantitative studies and 10 items for qualitative studies. Items for quantitative studies covered appropriate research design and methodology, sufficiently appropriate data analysis and control for confounders. Items for qualitative studies covered a clear research question and context, use of theoretical framework, systematic data collection and analysis and consideration of reflexivity.

Response options (and score) for each quality rating item for both research designs were 'yes' (2), 'partial' (1), or 'no' (0) [38]. For the quantitative studies, a 'not applicable' (N/ A) score was also used. There were three stages to calculate the overall score. Firstly, the total possible score was 28 minus (number of N/A's $\times 2$ ). Then the total score was (number of 'yes' $\times 2$ ) plus (number of 'partial' $\times 1$ ). The not 
applicable sections were excluded from the total score. Therefore the summary score was calculated by the total score divided by the total possible score. The final score for each qualitative study was calculated by: Total sum equalled (number of 'yes' $\times 2$ ) plus (number of 'partial' $\times 1$ ) divided by the total possible sum of 20 . The not applicable option was not available for the qualitative score [38].

Two researchers independently undertook quality ratings in a pilot of four studies (two quantitative and two qualitative) for rigour. These researchers then discussed and resolved any discrepancies before independently undertaking quality ratings for the remaining studies. A Kappa score was calculated as an indication of agreement between reviewers and then any differences in ratings for the remaining studies were then discussed and resolved. Articles were classified out of a maximum score of 1.0, with strong articles categorised as $>0.8$, moderate $(0.61-0.8)$ or weak $(<0.6)$, based on the categories used by Henry, Kyle, Bhandari, Chisholm, Griffiths and Bundy [42]. Although Henry et al. [42] used an amended version of Kmet et al.'s [38] quality rating system, these categories were used as they most accurately reflected the authors' opinion on the quality of the articles. The rating for each article is provided in Tables 1 (for search 1) and 3 (for search 2) in the Results section.

\section{Results}

In total, 10,171 studies were initially identified for the first research question and 1992 studies for the second research question. There were 18 studies regarding the first research question and eight studies regarding the second research question that were included in the final review. These low inclusion rates were due to a number of studies either not clearly defining sport or not providing specific results for sport participation. Details of this process can be found in Figs. 1 and 2 respectively. The themes that emerged from the quantitative and qualitative studies are presented concurrently in a convergent style [43] throughout this review.

\section{Determinants of sport participation for community dwelling older adults}

There were more qualitative studies $(n=10)$ than quantitative $(n=8)$ studies. The majority of the quantitative studies were cross-sectional $(n=5)$, with three longitudinal studies. Most of qualitative studies were interviews $(n=6)$, plus two studies utilising both ethnographic and interviews, one using photo elicitation and interviews and one study using photovoice and interview research methodology. The range of participants across included studies was six to 22,050. The majority of the studies were undertaken in Australia $(n=5)[13,14,20,23,44]$ and the USA $(n=5)[15-18,21]$, with one study undertaken respectively in Canada [22], England [45], Germany [46], The
Netherlands [47], New Zealand [19], Scotland [48], South Korea [49] and Sweden [50]. There were 13 studies that focused on the older adult age group, whilst three studies were non-specific to older adults, but reported age specific data. Details of the studies included in this section can be found in Table 1 .

The quality ratings ranged from 0.55 to 1 . Most articles were rated as strong articles $(n=10)$, with six as moderate and two as weak. The inter-rater reliability Kappa score was $0.66(p<0.001) 95 \%$ CI $(0.38,0.94)$, which is classified as a substantial agreement [51] between the two reviewers. Seven main themes emerged from these 18 articles, as did several sub-themes, as shown below. These themes are presented in the order of most to least frequently mentioned in the included articles with an overview provided in Table 2.

\section{Health determinants}

Health was the most frequently reported determinant for older adults' participation in sport, and there were two contrasting sub-themes: health as a positive outcome of sport participation; and physical health as a limitation to participation in sport.

There were six studies (one quantitative and five qualitative) which found that improved health was a positive outcome of sport participation. These articles reported that participants in Masters/Senior Games sport competitions $[13,15]$ and also in community sport clubs $[16,21,22,49]$ felt that participating in sport had assisted their physical $[13,15,16,21,22,49]$, mental or psychological $[13,16,21$, $22,49]$ and/or social [13, 15, 16, 21, 49] health. However, there were three studies (two quantitative and one qualitative) that reported that poor physical health limited the ability of older adults to participate in sport $[16,23,45]$.

\section{Negotiating the ageing process through sport}

Negotiating the ageing process through sport was the next most frequently mentioned theme, which was highlighted in the qualitative studies only. This theme also had two sub-themes: positive ageing discourse; and negotiating negative stereotypes of ageing.

Developing a positive ageing discourse through sport was discussed by participants across many different studies [13, 14, 16, 17, 21, 50]. For example, older adults reinforced their social identity through participating in sport [16], used sport to differentiate themselves from non-active older adults [17] or used sport as a mechanism to transform their identity from an ageing older adult to a competitive athlete [17].

Two studies reported that participants used sport to negotiate the negative stereotypes of ageing [13, 17]. In one study, participants celebrated that their behaviour challenged age-appropriate norms and disassociated themselves from the aged stereotype [13]. Furthermore, 


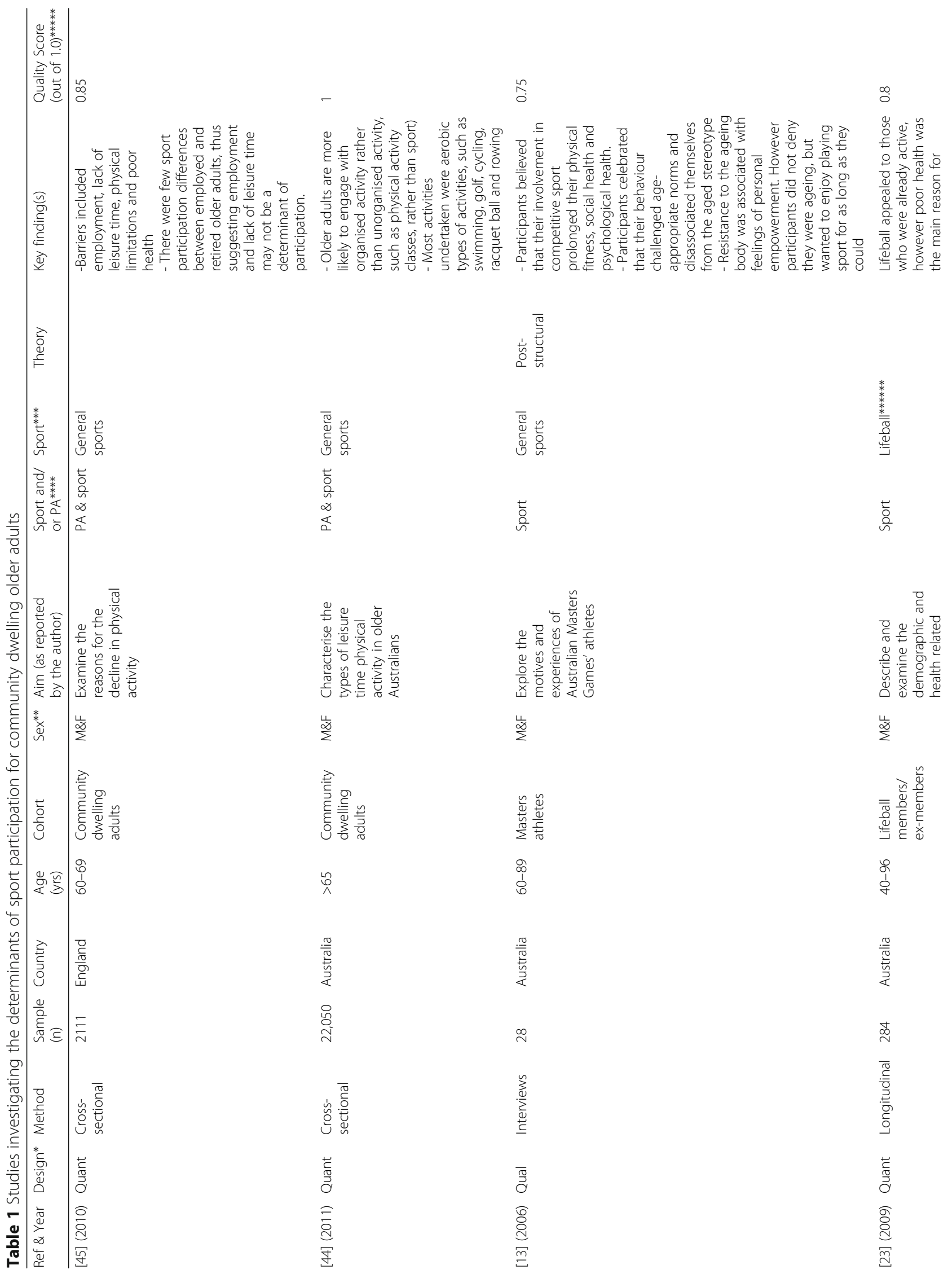




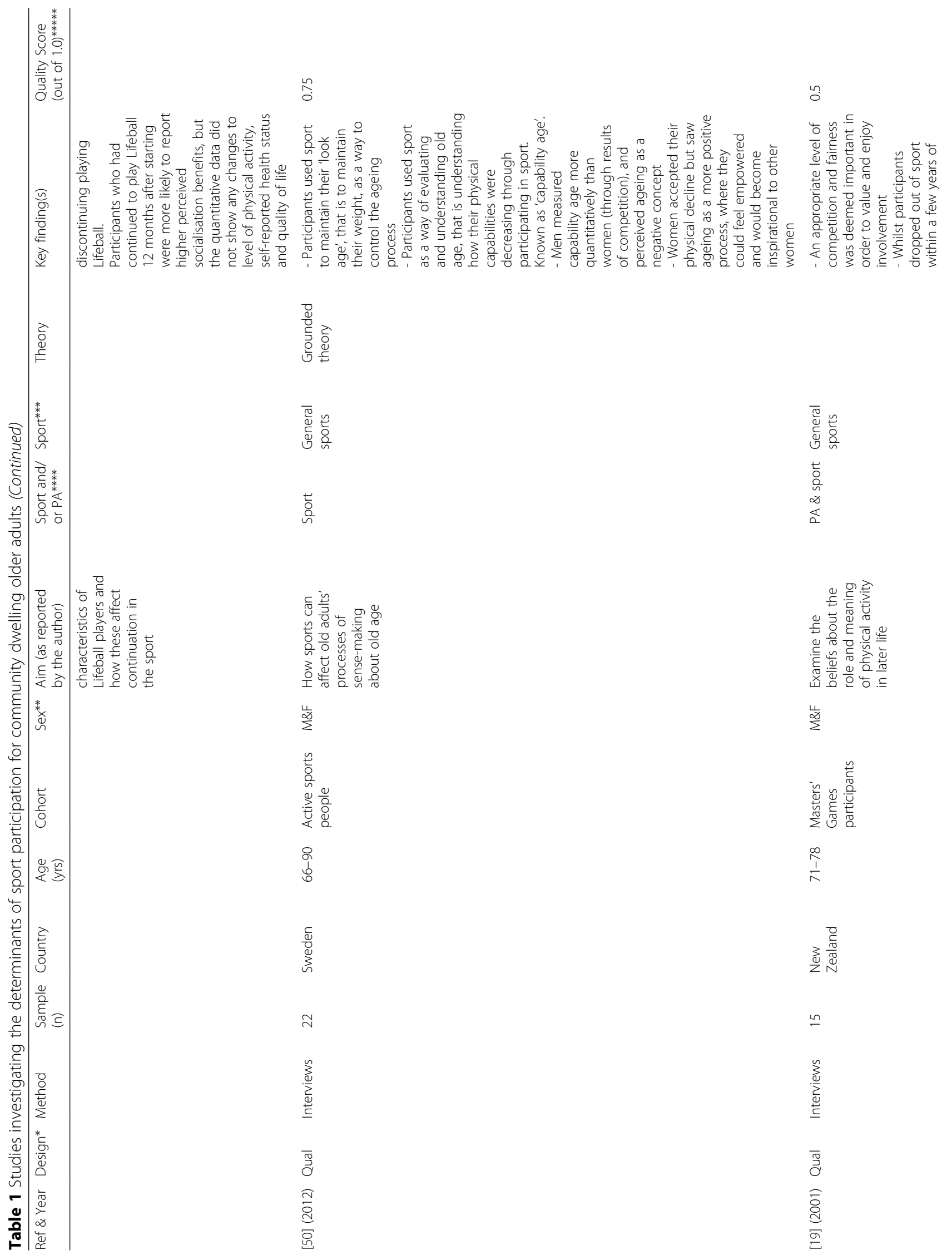




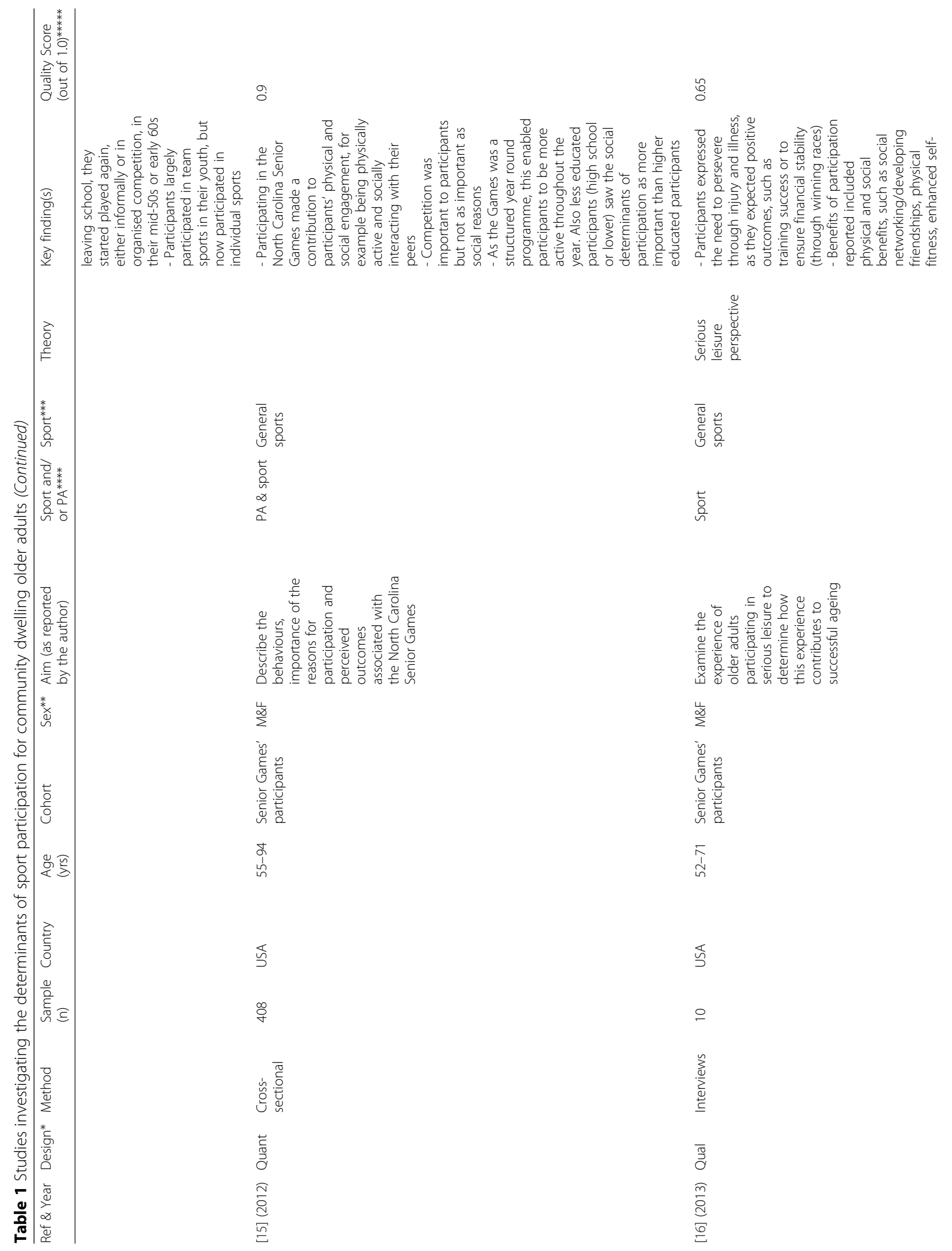




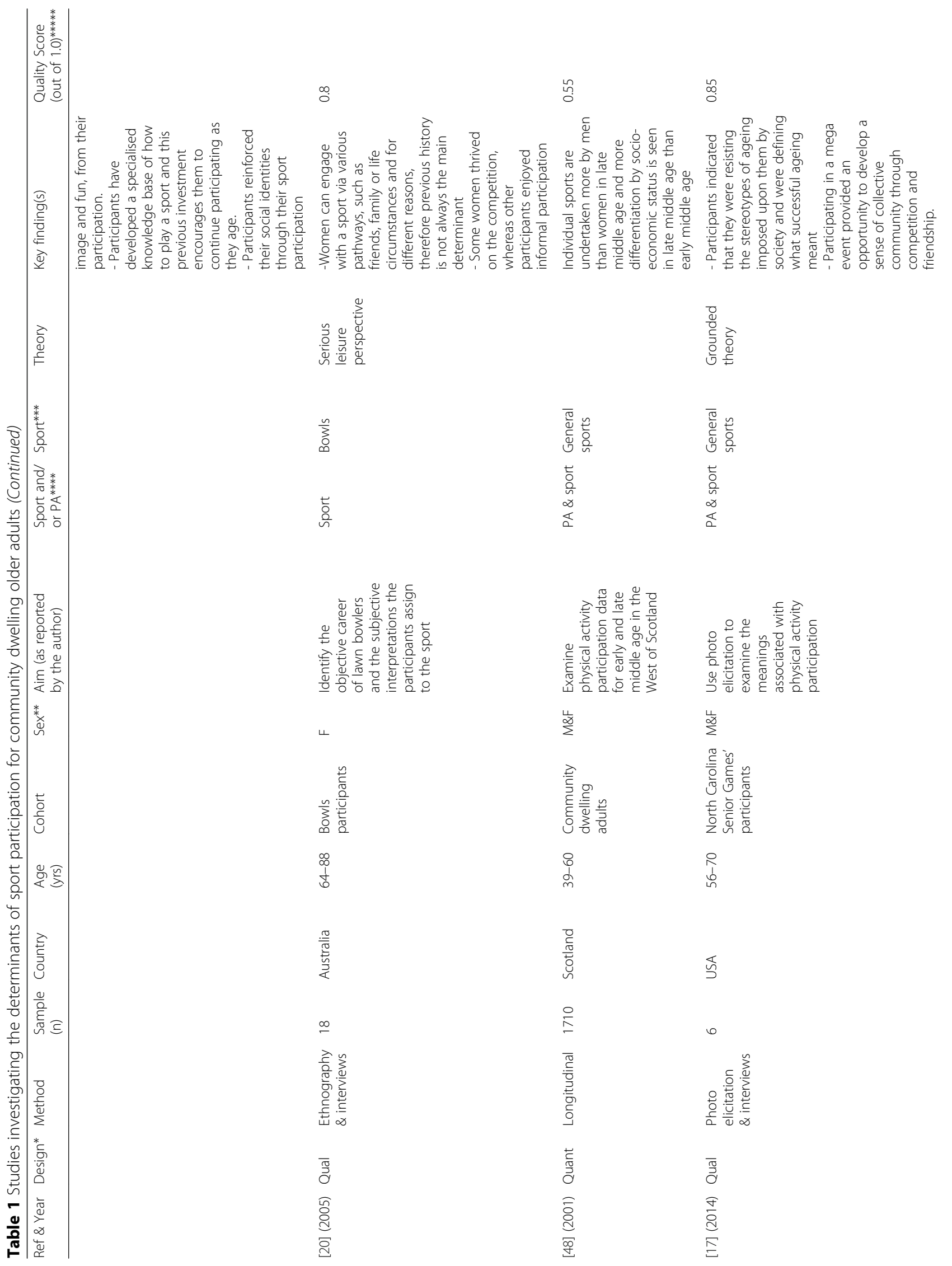




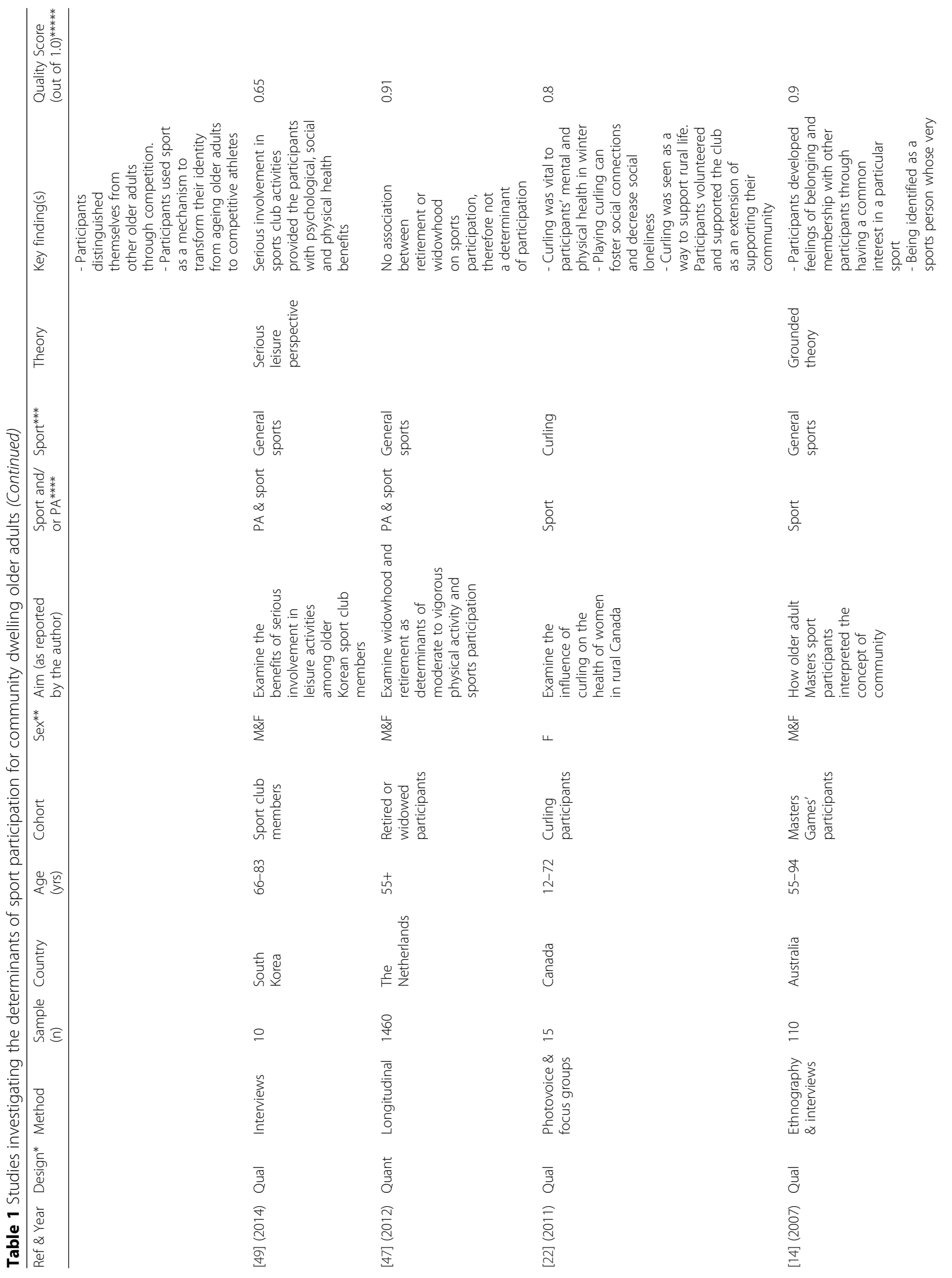




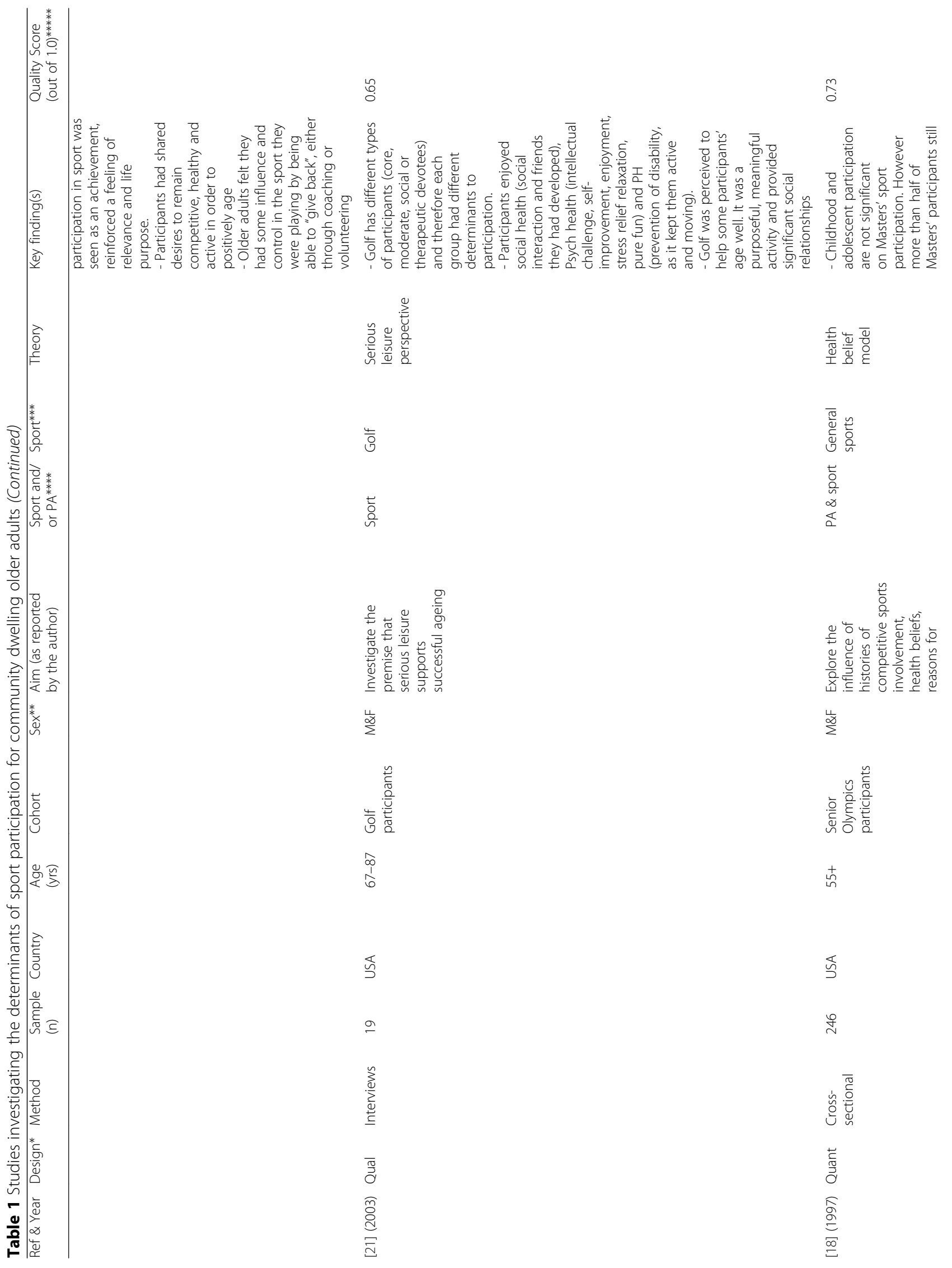




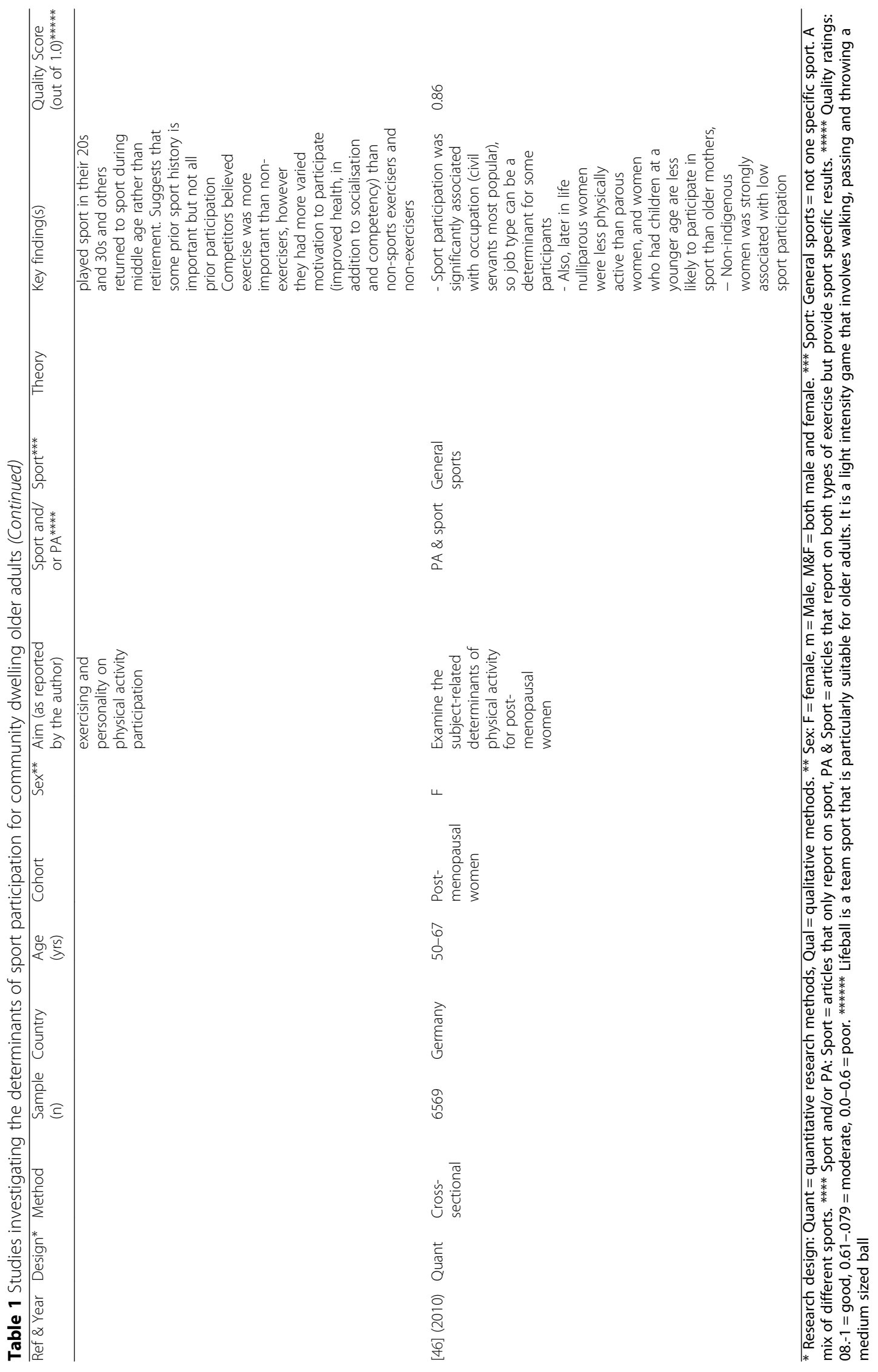


Table 2 Summary of themes for the determinants of sport participation for community dwelling older adults

\begin{tabular}{|c|c|c|}
\hline Theme & Sub-theme & Study \\
\hline \multirow[t]{2}{*}{ Health determinants } & Health as a positive outcome of sport participation & $13,15,16,21,22,49$ \\
\hline & Health as a limitation of sport participation & $16,23,45$ \\
\hline \multirow[t]{2}{*}{ Negotiating the ageing process through sport } & Positive ageing discourse & $13,14,16,17,21,50$ \\
\hline & Negotiating the negative stereotypes of ageing & 13,17 \\
\hline \multirow[t]{2}{*}{ Social/community connection } & Using sport to create/maintain a community & $14,17,22$ \\
\hline & Using sport to foster social connections & 14,22 \\
\hline \multirow{2}{*}{$\begin{array}{l}\text { Influence of prior sports history on current } \\
\text { sport participation }\end{array}$} & Positive influence of prior sports history & $16,18,23$ \\
\hline & $\begin{array}{l}\text { Prior sports history may not always be important } \\
\text { for current participation }\end{array}$ & 20,21 \\
\hline \multirow[t]{7}{*}{ Socio-demographic determinants } & Employment/retirement & $45,46,47$ \\
\hline & Ethnic background & 46 \\
\hline & Gender & 50 \\
\hline & Occupation & 46 \\
\hline & Parity & 46 \\
\hline & Socio-economic status & 48 \\
\hline & Marital status & 46,47 \\
\hline \multirow[t]{3}{*}{ Competition } & To value sport & $15,19,20$ \\
\hline & $\begin{array}{l}\text { To distinguish participating from non-participating } \\
\text { older adults }\end{array}$ & 17 \\
\hline & Ensure financial stability & 16 \\
\hline \multirow[t]{2}{*}{ Sport type } & Preference for individual sports & 19,48 \\
\hline & Preference for organised activity & 44 \\
\hline
\end{tabular}

several studies reported that sport was a purposeful and meaningful activity for older adults [14, 21, 50], whilst one study suggested that although their participants did not deny they were ageing, sport enabled them to resist their ageing body, which empowered them to enjoy playing sport for as long as they physically could [13].

\section{Social/community connection}

Using sport as a tool to develop a social/community connection for older adults was a common theme amongst three of the qualitative studies, with two subthemes emerging: using sport for the development and maintenance of community engagement for older adults; and using sport to foster social connections.

Two studies reported participant discussions of volunteering through sport or 'giving back' to the community. For example, one study suggested that supporting local sport clubs was seen as a way for older adults to support rural life/their local community [22], whilst another study reported that volunteering or coaching enabled participants to feel they had some influence or purpose in their sport [14]. For others, participating in a mega event provided an opportunity to develop a sense of collective community through competition and friendship [17].

The concept that sport can be used to foster social connections was discussed in two articles, one at a community sport club and one at a large sporting event. A study conducted in rural Canada suggested that playing curling could foster social connections and decrease social loneliness [22], whilst a study in Australia proposed that participants developed feelings of belonging and membership with other participants through having a common interest in a particular sport [14].

\section{Influence of prior sport history on current sport participation}

The influence of prior sport history emerged in five articles (two quantitative and three qualitative), with contrasting sub-themes: positive influence of past sport history; and that prior sport history may not always be important for current participation.

Three studies reported that prior sport history had a positive effect on current older adult sport participation $[16,18,23]$. For example, these positive influences could be having prior competency, skills and knowledge to participate in sport $[16,18]$, or that sport was attractive to those already active [23]. Specifically for Masters sport participation, prior sport participation was important for some but not all participants [18]. Conversely, two qualitative studies suggested that prior sport history may not always be important for current participation, as different determinants influenced their participation $[20,21]$. 


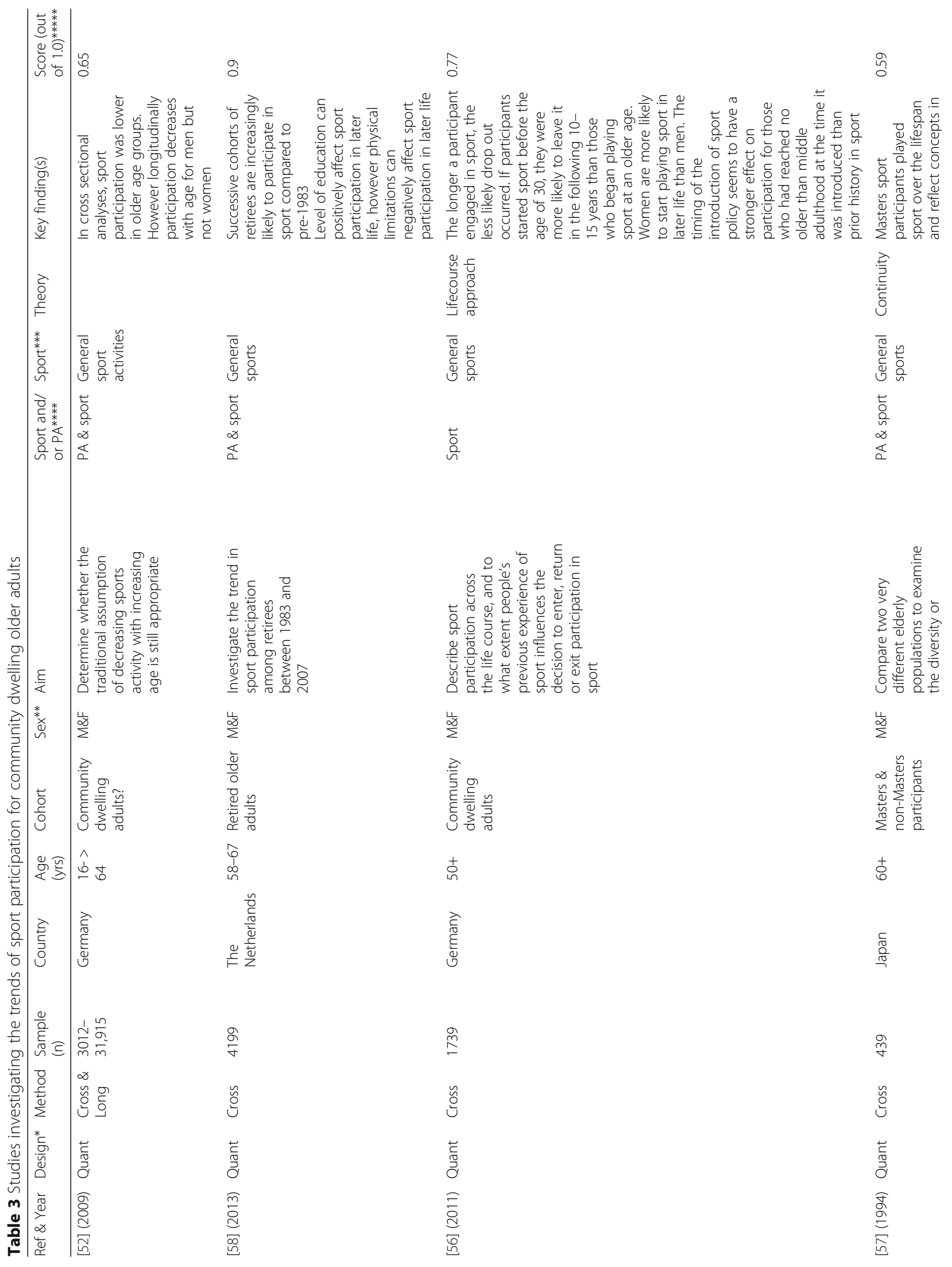




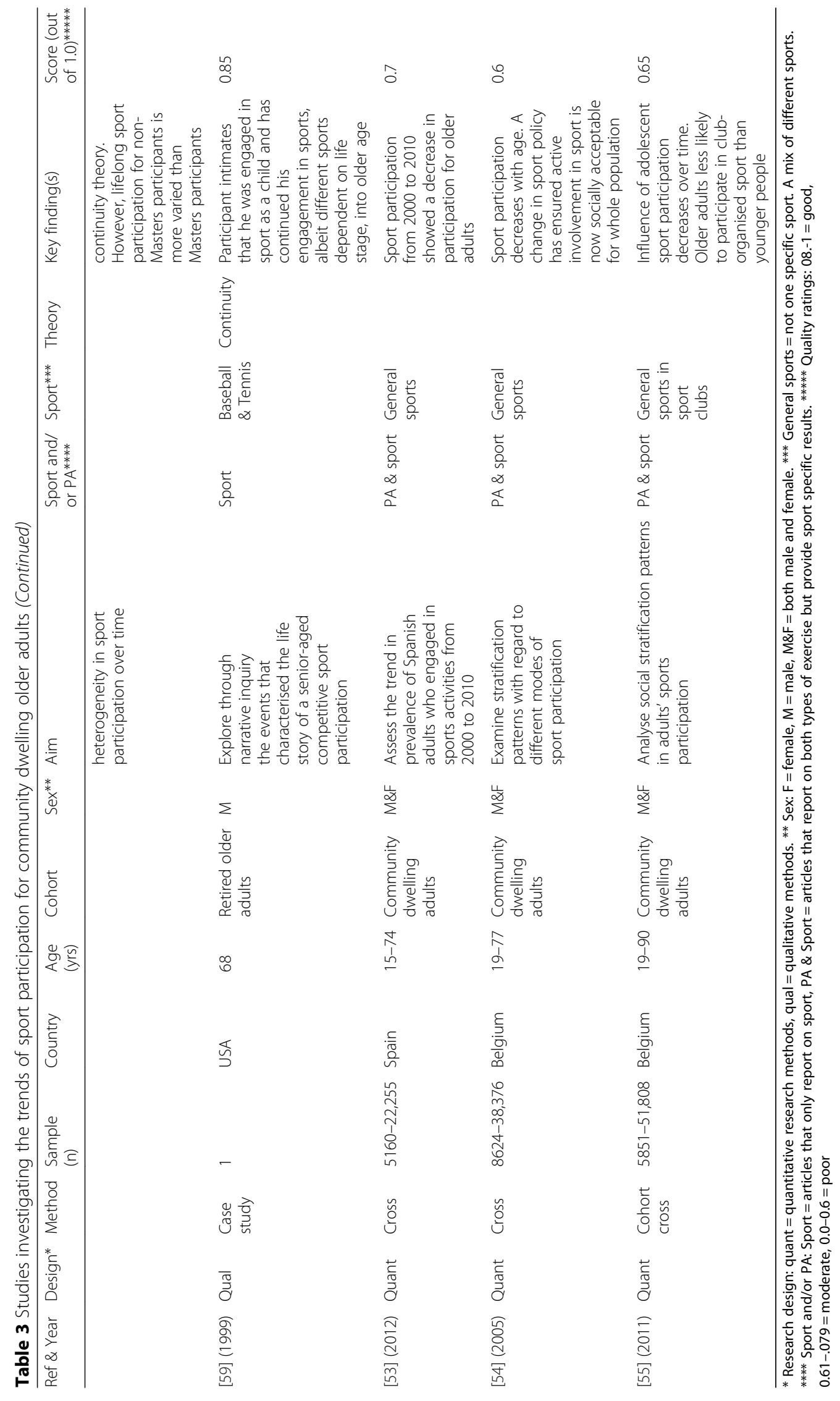




\section{Socio-demographic determinants}

There were seven sub-themed socio-demographic determinants for sport participation that emerged from the quantitative $(n=6)$ and qualitative $(n=1)$ studies: employment and retirement, occupation, socio-economic status, ethnicity, gender, parity and marital status.

The influence of employment and retirement on sport participation was discussed in three studies [45-47]. One study found that retirement was not an important determinant of participation [47], whilst another study reported that employment was a perceived barrier [45]. A study from Germany reported that sport participation was significantly associated with occupation [46], with civil servants more likely to be engaged in sports compared to other types of workers, and another study suggested that a more favourable socio-economic status was a positive determinant in late middle age participation [48].

There was limited research that reported the influence of gender, ethnicity and parity on older adult sport participation. These studies reported that the ethnic background of participants was an important factor in one study. Being a non-indigenous female in Germany was strongly associated with low sport participation compared with indigenous females [46]. Gender differences in participation also emerged as a determinant from the one qualitative study. It was reported that men used their sport participation to measure their capability age, essentially assessing how their physical capabilities were decreasing, more quantitatively than women, largely through results in competition. Whilst the older women in this study accepted their physical decline, they saw ageing as a more positive process, where they could feel empowered and would become inspirational to other older women by participating in sport [50]. Parity was another socio-demographic sub-theme to emerge, with one study suggesting that women who had children at a younger age were less likely to participate in sport than older mothers [46].

Two studies assessed marriage, with one study suggesting that there was no association between marital status and sport participation [46], whilst another study showed no association between widowhood and sport participation [47].

\section{Competition}

The importance, and enjoyment, of competition was reported in five studies (four qualitative and one quantitative) $[15-17,19,20]$. The role of competition was found to enable older adults to enjoy and value sport participation [19] or also to distinguish participants from older adults who did not play competitive sport [17].

\section{Type of sport structure}

This theme included two sub-themes: preference for individual sports and preference for organised activity.
Two studies (one quantitative and one qualitative) suggested that specifically middle aged men [48] and older adults in general [19], preferred participation in individual rather than team sports, whilst another quantitative study proposed that the 'older old' were more likely to engage with organised activity rather than unorganised activity [44].

\section{Trends in sport participation for community dwelling older adults}

Relating to trends in sport participation, the majority of studies were quantitative (7), with one qualitative study. Most quantitative studies were cross-sectional $(n=5)$, one utilised both cross-sectional and longitudinal methods, and one was a cohort cross sectional study. The single qualitative study was an individual case study. A number of included studies did not provide overall sample size [52-55], however the number of participants across the quantitative studies that did report overall sample sizes ranged from 439 to 4199 . The majority of the studies were located in Germany $(n=2)[52,56]$, and Belgium $(n=2)$, [53, 54] with other studies undertaken in [54, 55] Japan $(n=1)$ [57], The Netherlands $(n=1)$ [58], Spain $(n=1)$ [53], and the USA $(n=1)$ [59] respectively. Four studies were non-specific to older adults, but reported age specific data, whilst four studies focused solely on the older adult age group. Details of the eight studies examining trends in sport participation for older adults can be found in Table 3 .

Quality ratings for these studies ranged from 0.59 to 0.90 . Most studies were rated as moderate $(n=4)$, with two strong studies and two weak studies. The inter-rater reliability Kappa score was $0.46(p<0.004) \quad 95 \%$ CI $(0.030,0.88)$, which is classified as a moderate agreement between the reviewers [51]. Three main themes and several subthemes emerged from the study review, as detailed in Table 4 below.

Table 4 Summary of themes for the trends of sport participation for community dwelling older adults

\begin{tabular}{lll}
\hline Theme & Sub-theme & Study \\
\hline $\begin{array}{l}\text { Effect of historical sport } \\
\text { participation on trends }\end{array}$ & Continuity theory & 57,59 \\
$\begin{array}{l}\text { Sport participation across } \\
\text { the lifespan }\end{array}$ & $\begin{array}{l}\text { Sport participation } \\
\text { decreases with age }\end{array}$ & $55,56,57$ \\
& $\begin{array}{l}\text { Sport participation does } \\
\text { not always decrease }\end{array}$ & 52,54 \\
& $\begin{array}{l}\text { with age } \\
\text { Policy/programming }\end{array}$ & \\
Demographic impacts on & Education & 58 \\
sport trends & Health & 58 \\
& Gender & 56 \\
& Type of sport & 55 \\
\hline
\end{tabular}




\section{Effect of historical sport participation on trends}

There were four studies (three quantitative and one qualitative) that reported the effect of previous sport participation, such as in childhood, adolescence or early adulthood, on current participation [55-57, 59]. Two sub-themes emerged from this theme: Continuity theory and engagement in sport.

Continuity theory, which states that adults use strategies linked to their past experiences (for example, sport participation) to adapt to the ageing process [60], was a key theme found in several studies. Two studies found the role of participation in sport specifically, or physical activity more generally, as a child or adolescent influenced participation in sport as an older adult $[57,59]$.

Trends in sport engagement were found to be more diverse in three other quantitative studies. For example, participation for some older adults was more varied [57]. One study found that the influence of adolescent participation decreased over time [55], whilst another study suggested that those who started playing sport at an older age were less likely to drop out than participants who had started playing at a younger age, for example, during adolescence [56].

\section{Sport participation across the lifespan}

Four quantitative studies examined whether sport participation decreased with age, finding contrasting results. In the cross-sectional studies, it was reported that sport participation was lower in people with higher age [52-54]. However, one longitudinal study found that whilst sport participation decreased with age for men, it did not necessarily decrease for women [52]. Conversely, one study found that successive cohorts of retirees are increasingly likely to participate in sport [58].

\section{Demographic impacts on sport trends}

There were five quantitative studies that observed demographic impacts on sport trends, with sub-themes of policy/programming, education, health, gender and type of sport structure. Two studies focused on sport policy, with both studies suggesting that the 'Sport for All' policies established in the 1960s, which have promoted sport participation for health and social benefits, had a strong effect on sport participation levels $[54,56]$. Other studies stated that level of education can positively affect sport participation in later life [58], physical limitations can negatively affect sport participation in later life [58] and older adults were less likely to participate in cluborganised sport than younger people [55]. One study also suggested that women were more likely to start playing sport in later life than men [56].

\section{Discussion}

This is the first systematic literature review to explore the determinants and trends regarding older adults' sport participation. Given the increasing ageing population of Western nations and the anticipated associated decline in health, it is important to investigate the potential of diverse forms of physical activity to enable age appropriate opportunities for older adults to undertake enjoyable exercise as they age.

\section{Determinants of sport participation for community dwelling older adults}

There was a variety of common factors associated with sport participation in older adults, including health determinants, negotiating the ageing process through sport, social/community connection, the influence of prior sport history on current sport participation, socio-demographic determinants, competition and sport type. The most frequently reported themes were health determinants and negotiating the ageing process through sport.

It is not surprising that health was the most frequently mentioned determinant. An increasing ageing population is likely to increase the risk of chronic disease for the individual, and is also predicted to result in higher public health expenditure $[1,61]$, thus becoming a priority action area for governments. This review has shown that sport can provide positive health benefits for older adults, but also that sport participation may be more difficult for older adults as they age, because ageing is typically associated with a decline in health. This is especially prevalent for certain sports, such as contact or physically demanding sports. This concept is similarly reflected in studies on generic physical activity and older adults [62-64]. In this review, it is interesting to note that health as a motivation to exercise was mostly supported by data of older adults who played sport either in a community sport club or at Masters/Senior Games competitions [13, 15, 16, 21, 22, 49].

Poor health as a limitation to participation is a unique determinant for this age group and needs to be taken into consideration. As such, to enable older adults to derive the health benefits sport can provide, age appropriate playing opportunities are required, especially in more exertive sports, to accommodate for older adults who may have age related reduced physical capabilities. However, previous research has highlighted that many sports do not prioritise older adults specifically [31], but there is an opportunity for sport to be promoted as a novel intervention for health promotion in older adults.

Similarly to health determinants, this study also highlights another unique concept for older adults; that is, the role of negotiating the ageing process through sport. Studies in this review suggest older adults use sport to distance themselves from the older adult societal 
stereotype and/or reinforced their social identity through sport. For example, some older adults used sport to differentiate themselves from non-active older adults or used sport as a mechanism to transform their identity from an ageing older adult to a competitive athlete [17]. This concept has been previously identified by Dionigi's [29] narrative literature review on the psychosocial and sociological issues of sport and ageing. The relevant studies on this theme in both Dionigi's [29] review and this systematic review were all qualitative, as the data was mainly explorative and this concept may be difficult to measure quantitatively. However, it could be interesting to further develop this and to explore if quantitative evidence can reinforce this concept on a wider scale. Also, most of the current data on this determinant were for Masters or Senior Games sport participation, meaning older adults playing competitive sport at large scale events, but not in community level sport. Therefore further research should be conducted in community sport to investigate if similar concepts emerge in an informal and more social sport setting. This could enable sporting organisations to further promote sport as an attractive option for older adults to be physically active.

There were only a small number of studies examining socio-demographic factors associated with participation. Previously it has been found that socio-demographic determinants, such as gender, socio-economic status and ethnicity, are major factors associated with sport participation in other age groups, such as children/adolescents [65] and adults [66]. Conversely, from this review, it would appear that health as a determinant of older adult participation has more traction because it has public health and economic value. However, if organisations want to increase the proportion of older adults' participating in sport to improve their health, then more knowledge on other potential determinants is needed, starting with sociodemographic determinants such as gender and education. In addition, as older adults have different life priorities and different impacts on their time than younger adults, it should be examined which age specific socio-demographic factors are associated with participation. For example, the unique impact of work/retirement as a determinant was only researched in three studies. More research on this is needed to further understand its potential influence on older adult sport participation and to be able to use this to identify subgroups of older people who may be interested in participating in sport.

\section{Trends of sport participation for community dwelling older adults}

Overall there were fewer studies that investigated participation trends than participation determinants. From those participation trend studies, three main themes emerged. These related to the effect of historical sport participation on trends, sport participation across the lifespan and demographic impacts on trends.

This review found that in general, participation in sport declines with age. This is a similar finding to some generic physical activity research [67, 68]. Furthermore, historical/past participation in sport was found to be a determinant of current participation, which is also in line with determinants reported in previous physical activity [69] and sport research [70]. However, some themes from this review suggested that participation did not always decrease with age, which is also reflected in some adult leisure-time physical activity studies. These studies have reported that leisure-time physical activity for both men and women was actually increasing over time [71, 72]. This demonstrates the heterogeneity of this age group and can encourage sporting organisations to promote sport participation to older adults, regardless of their prior sport history $[19,73]$.

\section{Correlation between the research questions}

The two research questions were amalgamated in this one systematic review because determinants can influence patterns of sport participation either positively or negatively over the lifespan. Additionally, some of the reviewed trend studies sought to identify factors, for example, demographics, that influenced patterns or trends over time. Overall, there were a number of findings that linked the two research areas.

Conflicting data on the influence of prior sport participation emerged for both research questions. As proposed earlier in this discussion, this suggests that older adults are a diverse age group who can be attracted to sport for the first time at an older age, if appropriate participation opportunities are provided.

Socio-demographic factors also emerged in both research areas, though the number of studies was relatively small. As these influences, such as gender, socioeconomic status, physical environment and family background, have been shown to be influential for other age groups [74-76], it is recommended that more research on these influences is undertaken to further investigate these findings and understand their importance (or lack of) for this age group. Furthermore, the influence of retirement, a unique theme for older members of this age group, was inconclusive. This influence reported conflicting results between the one determinant study and one trends study that reported on this, thus further research is recommended for this theme to resolve this conflict. It is recommended that sporting organisations consider these socio-demographic influences when developing appropriate playing opportunities for this age group.

Health was a well-researched area for determinants, but there was only one trends study that included health. 
This trends study focused on how physical limitations can negatively affect sport participation in later life, which corresponded with some of reviewed determinant studies. These results reflect that older adults, as a group, are more likely to experience various health conditions that may affect their participation in some sports, such as those requiring high exertion or physical contact. There are unique determinants across different times within the lifespan, for example a study on sport participation for adolescents [77] have shown that having fun with friends and having role models were important determinants of sport participation. Whilst some of these determinants are the same for older adults, the results in this review suggest that appropriate opportunities should be developed in some sports for those with health limitations (such as adapted sport and/or social sport). This is in addition to age appropriate opportunities for those without debilitating health conditions, to also enable these older adults to continue playing either competitive or social sport with their peers.

\section{Methodological recommendations}

According to Kmet et al.'s guidelines [38], the majority of the studies across both research areas were identified as high quality, however this research area could benefit from a number of methodological improvements. Qualitative research needs to better acknowledge the importance and potential impact of reflexivity, and quantitative research would benefit from more longitudinal designs to expand on the current, largely cross sectional, findings.

Many of the studies included in this systematic review were on Masters/Senior Games sport. That is, a competitive form of sport, rather than community-based recreational forms such as club sport. In the interest of population health strategies, the role of sport in the general community for older adults is important to understand. Whilst there were some studies on community sport, these tended to be sport specific and focused on traditional older adults' sport, such as golf and bowls. Community sporting organisations can benefit from understanding the trends and determinants of participation, to better cater specific products/programmes to the needs of older adults. Community sport in recent years has developed and implemented specific modified sport products for very young children, to meet their developmental needs [78]. Given the different potential health limitations of some older adults, partial modifications of sports for older adults is a potential strategy to encourage their increased participation, at least for sports with high exertion or physical contact.

\section{Strengths and limitations of this review}

This review presented two research questions to provide context and enable direct comparison between two important influences for older adults' sport participation. It also comprised of both qualitative and quantitative studies to ensure a breadth of research was included. However, it also had a number of limitations. Whilst the search strategy was comprehensive, it did not include grey literature or non-English language articles. Also, whilst the quality rating system used enabled both types of studies to be assessed, the assessment criteria for the quantitative studies were not as rigorous as other quantitative rating systems, which may have impacted the assessment scores.

\section{Conclusion}

This study brought together a range of diverse research investigating the factors associated with sport participation in older adults. As the populations of Western nations continue to age, it is important to explore different ways that older adults can be physically active in their leisure-time. In conclusion, this review highlights that older adults do use sport to improve their health, but at the same time, due to decreased health in general with ageing, poor health can equally be a barrier to participation. It is recommended that sporting organisations use this review to understand the determinants and trends of older adult participation, by providing both social play and competitive appropriate opportunities. However, it is essential that organisations ensure that these opportunities also cater for older adults who may have potential health limitations, to ensure older adults who enjoy sport can continue to participate as they age.

\section{Acknowledgements}

Not applicable.

\section{Funding}

CRJ was supported by an Australian Sports Commission-ISEAL Victoria University PhD Scholarship. JVU was supported by an Australian Sports Commission-ISEAL Victoria University Senior Research Fellowship.

\section{Availability of data and materials}

Not applicable.

\section{Authors' contributions}

CRJ contributed to the study design, the review of literature, analysis of literature, manuscript conceptualisation and preparation. RME contributed to the study design, manuscript conceptualisation and preparation. HW contributed to the study design and manuscript preparation. GO contributed to the review of literature, analysis of literature and manuscript preparation. JGZU contributed to the study design and manuscript preparation. All authors read and approved the final manuscript.

\section{Ethics approval and consent to participate} Not applicable.

Consent for publication Not applicable.

Competing interests

The authors declare that they have no competing interests. 


\section{Publisher's Note}

Springer Nature remains neutral with regard to jurisdictional claims in published maps and institutional affiliations.

\begin{abstract}
Author details
'Institute of Sport, Exercise and Active Living (ISEAL),Victoria University, Melbourne, VIC 8001, Australia. ${ }^{2}$ Facility of Health, Federation University, PO Box 663, Ballarat, VIC 3353, Australia. ${ }^{3}$ Department of Movement Sciences, Physical Activity, Sports and Health Research Group, KU Leuven - University of Leuven, B-3000 Leuven, Belgium.
\end{abstract}

Received: 25 January 2017 Accepted: 29 November 2017 Published online: 22 December 2017

\section{References}

1. World Health Organisation, Global health and ageing. 2011, US National Institute on Ageing Bethesda.

2. Vogeli C, Shields AE, Lee TA, Gibson TB, Marder WD, Weiss KB, Blumenthal D. Multiple chronic conditions: prevalence, health consequences, and implications for quality, care management, and costs. J Gen Intern Med. 2007;22(3):391-5.

3. Booth FW, Roberts CK, Laye MJ. Lack of exercise is a major cause of chronic diseases. Comprehensive Physiology. 2012;

4. Paterson, D.H., Jones G.R., and Rice C.L., Ageing and physical activity: evidence to develop exercise recommendations for older adults. This article is part of a supplement entitled 'Advancing physical activity measurement and guidelines in Canada: a scientific review and evidence-based foundation for the future of Canadian physical activity guidelines', co-published by Applied Physiology, Nutrition, and Metabolism and the Canadian Journal of Public Health.

5. Bishop NA, Lu T, Yankner BA. Neural mechanisms of ageing and cognitive decline. Nature. 2010;464(7288):529-35.

6. Sirven N, Debrand T. Social participation and healthy ageing: an international comparison using SHARE data. Soc Sci Med. 2008:67(12):2017-26.

7. Dunsky A, Netz Y. Physical activity and sport in advanced age: is it risky?-a summary of data from articles published between 2000-2009. Current Aging Science. 2012;5(1):66-71.

8. Koeneman MA, Verheijden MW, Chinapaw MJM, Hopman-Rock M Determinants of physical activity and exercise in healthy older adults: a systematic review. Int J Behav Nutr Phys Act. 2011;8(1):1.

9. Sun F, Norman IJ, While AE. Physical activity in older people: a systematic review. BMC Public Health. 2013;13(1):449.

10. Taylor AH, Cable NT, Faulkner G, Hillsdon M, Narici M, Van Der Bij AK. Physical activity and older adults: a review of health benefits and the effectiveness of interventions. J Sports Sci. 2004;22(8):703-25.

11. Allender S, Cowburn G, Foster C. Understanding participation in sport and physical activity among children and adults: a review of qualitative studies. Health Educ Res. 2006;21(6):826-35.

12. Blake H, Mo P, Malik S, Thomas S. How effective are physical activity interventions for alleviating depressive symptoms in older people? A systematic review. Clin Rehabil. 2009:23(10):873-87.

13. Dionigi R. Competitive sport as leisure in later life: negotiations, discourse, and aging. Leis Sci. 2006;28(2):181-96.

14. Lyons K, Dionigi R. Transcending emotional community: a qualitative examination of older adults and masters' sports participation. Leis Sci. 2007:29(4):375-89.

15. Henderson KA, Casper J, Wilson BE, Dern L. Behaviors, reason, and outcomes perceived by senior games participants. Journal of Park \& Recreation Administration. 2012;30(1):19-35.

16. Heo J, Culp B, Yamada N, Won Y. Promoting successful aging through competitive sports participation: insights from older adults. Qual Health Res. 2013;23(1):105-13.

17. Kelley K, Little S, Jong Seon L, Birendra KC, Henderson K. Articulating meanings of positive adjustment to aging through physical activity participation among older adults. Journal of Park \& Recreation Administration. 2014;32(1):63-79.

18. Smith CL, Storandt M. Physical activity participation in older adults: a comparison of competitors, noncompetitors, and nonexercisers. Journal of Aging \& Physical Activity. 1997;5(2):98

19. Grant BC. 'You're never too old': beliefs about physical activity and playing sport in later life. Ageing Soc. 2001;21(06):777-98.

20. Heuser L. We're not too old to play sports: the career of women lawn bowlers. Leis Stud. 2005;24(1):45-60.
21. Siegenthaler KL, O'Dell I. Older golfers: serious leisure and successful aging. World Leisure Journal. 2003:45(1):45-52.

22. Leipert BD, Plunkett R, Meagher-Stewart D, Scruby L, Mair H, Wamsley K. I can't imagine my life without it! curling and health promotion: a photovoice study. Can J Nurs Res. 2011;43(1):60-78.

23. Green S, Campbell E, Barnett L, Mitchell R, Radvan D, Van Beurden E. Promoting a team ball game (lifeball) to older people: who does this game attract and who continues. Health Promot J Austr. 2009;20(2):120-6.

24. Martin KA, Sinden AR. Who will stay and who will go? A review of older adults' adherence to randomized controlled trials of exercise. J Aging Phys Act. 2001;9(2):91-114.

25. Australian Sports Commission, ASC recognition. What is defined as a sport? [online] Available from http://www.ausport.gov.au/supporting/nso/asc_ recognition [Accessed 10 August 2015]. 2009.

26. Eime RM, Young JA, Harvey JT, Charity MJ, Payne WR. A systematic review of the psychological and social benefits of participation in sport for children and adolescents: informing development of a conceptual model of health through sport. Int J Behav Nutr Phys Act. 2013;10(1):1.

27. Eime RM, Young JA, Harvey JT, Charity MJ, Payne WR. A systematic review of the psychological and social benefits of participation in sport for adults: informing development of a conceptual model of health through sport. Int J Behav Nutr Phys Act. 2013;10(135):14.

28. Oja P, Titze S, Bauman A, De Geus B, Krenn P, Reger-Nash B, Kohlberger T. Health benefits of cycling: a systematic review. Scand J Med Sci Sports. 2011;21(4):496-509.

29. Dionigi RA. The competitive older athlete: a review of psychosocial and sociological issues. Topics in Geriatric Rehabilitation. 2016;32(1):55-62.

30. Pike ECJ. Assessing the sociology of sport: on age and ability. Int Rev for the Sociology of Sport. 2015;50(4-5):570-4.

31. Jenkin CR, Eime RM, Westerbeek H, O'Sullivan G, van Uffelen JGZ. Are they 'worth their weight in gold'? Sport for older adults: benefits and barriers of their participation for sporting organisations. Int J Sport Policy and Politics. 2016:1-18.

32. Eime R, Payne W, Harvey J. Trends in organised sport membership: impact on sustainability. J Sci Med In Sport/Sports Med Aus. 2009;12(1): 123-9.

33. Gray S. Team club sports clubs for adults: A model. Am Assoc Behavorial Social Sci Online J. 2004:7:44-8.

34. Eime, R.M., Harvey, J.T., Charity, M.J., Casey, M.M., Westerbeek, H. and Payne, W.R., Age profiles of sport participants. BMC Sports Science, Medicine and Rehabilitation, 2016. 8(1): p. 1.

35. Condello G, Puggina A, Aleksovska K, Buck C, Burns C, Cardon G, Carlin A, Simon C, Ciarapica D, Coppinger T. Behavioral determinants of physical activity across the life course: a "DEterminants of Dlet and physical ACtivity"(DEDIPAC) umbrella systematic literature review. Int J Behav Nutr Phys Act. 2017;14(1):58.

36. Eime RM, Sawyer N, Harvey JT, Casey MM, Westerbeek H, Payne WR. Integrating public health and sport management: sport participation trends 2001-2010. Sport Manage Rev. 2015;18(2):207-17.

37. Eime RM, Harvey JT, Sawyer NA, Craike MJ, Symons CM, Payne WR. Changes in sport and physical activity participation for adolescent females: a longitudinal study. BMC Public Health. 2016;16(1):533.

38. Kmet, L.M., R.C. Lee, and L.S. Cook, Standard quality assessment criteria for evaluating primary research papers from a variety of fields. 2004, Alberta Heritage Foundation for Medical Research Edmonton.

39. Légaré F, Ratté S, Gravel K, Graham ID. Barriers and facilitators to implementing shared decision-making in clinical practice: update of a systematic review of health professionals' perceptions. Patient Educ Couns. 2008:73(3):526-35.

40. Wu O, Bayoumi N, Vickers MA, Clark P. ABO $(\mathrm{H})$ blood groups and vascular disease: a systematic review and meta-analysis. J Thromb Haemost. 2008; 6(1):62-9.

41. Squires JE, Estabrooks CA, Gustavsson P, Wallin L. Individual determinants of research utilization by nurses: a systematic review update. Implement Sci. 2011;6(1):1.

42. Henry AL, Kyle SD, Bhandari S, Chisholm A, Griffiths CEM, Bundy C. Measurement, classification and evaluation of sleep disturbance in psoriasis: a systematic review. PLoS One. 2016;11(6):e0157843.

43. Pluye $\mathrm{P}$, Hong QN. Combining the power of stories and the power of numbers: mixed methods research and mixed studies reviews. Public Health. 2014;35(1):29. 
44. Merom D, Carmen C, Kamalesh V, Adrian B. How diverse was the leisure time physical activity of older Australians over the past decade? J Sci Med Sport. 2012;15(3):213-9.

45. Chaudhury $M$, Shelton N. Physical activity among 60-69-year-olds in England: knowledge, perception, behaviour and risk factors. Ageing \& Society. 2010;30(8):1343-55.

46. Steindorf K, Chang-Claude J, Flesch-Janys D, Schmidt ME. Determinants of sports, cycling, walking and overall leisure-time physical activity among postmenopausal women in Germany. Public Health Nutr. 2010; 13(11):1905-14.

47. Koeneman MA, Chinapaw MJM, Verheijden MW, van Tilburg TG, Visser M, Deeg DJH, Hopman-Rock M. Do major life events influence physical activity among older adults: the longitudinal aging study Amsterdam. Int J Behav Nutr Phys Act. 2012;9

48. Hunt K, Ford G, Mutrie N. Is sport for all? Exercise and physical activity patterns in early and late middle age in the west of Scotland. Health Educ. 2001;101(4):151-8

49. Kim J, Yamada N, Heo J, Han A. Health benefits of serious involvement in leisure activities among older Korean adults. Int J Qualitative Studies on Health and Well-being. 2014;9

50. Eman J. The role of sports in making sense of the process of growing old. J Aging Stud. 2012;26(4):467-75.

51. Landis JR, Koch GG. The measurement of observer agreement for categorical data. Biometrics. 1977:159-74.

52. Breuer $C$, Wicker P. Decreasing sports activity with increasing age? Findings from a 20-year longitudinal and cohort sequence analysis. Res Q Exerc Sport. 2009;80(1):22-31.

53. Palacios-Ceña D, Fernandez-de-Las-Peñas C, Hernández-Barrera V, JiménezGarcia R, Alonso-Blanco C, Carrasco-Garrido P. Sports participation increased in Spain: a population-based time trend study of 21381 adults in the years 2000, 2005 and 2010. Br J Sports Med. 2012;46(16):1137-9.

54. Scheerder, J., B. Vanreusel, and Taks M., Stratification patterns of active sport involvement among adults: social change and persistence. Int Rev for the Sociology of Sport, 2005. 40(2): p. 139-162;273;375;277-278.

55. Scheerder J, Vos S. Social stratification in adults' sports participation from a time-trend perspective. Results from a 40-year household study. Eur J Sport and Soc. 2011;8(1-2):31-44.

56. Engel C, Nagel S. Sports participation during the life course. Eur J Sport and Soc. 2011;8(1-2):45-63.

57. Harada M. Early and later life sport participation patterns among the active elderly in Japan. J Aging Phys Act. 1994;2(2):105-14.

58. Cozijnsen R, Stevens NL, Van Tilburg TG. The trend in sport participation among Dutch retirees, 1983-2007. Ageing Soc. 2013;33(04):698-719.

59. Langley DJ, Knight SM. Continuity in sport participation as an adaptive strategy in the aging process: a lifespan narrative. J Aging \& Physical Activity. 1999;7(1):32.

60. Atchley RC. A continuity theory of normal aging. The Gerontologist. 1989; 29(2):183-90.

61. Australian Department of Treasury \& Finance, Australia to 2050: Future Challenges. Intergenerational report series no. 3. 2010, Canberra: Treasury.

62. Juarbe T, Turok XP, And Pérez-stable EJ. Perceived benefits and barriers to physical activity among older Latina women. West J Nurs Res. 2002;24(8): 868-86

63. Bethancourt HJ, Rosenberg DE, Beatty T, Arterburn DE. Barriers to and facilitators of physical activity program use among older adults. Clin Med Res. 2014;12(1-2):10-20.

64. Patel A, Schofield GM, Kolt GS, Keogh J. Perceived barriers, benefits and motives for physical activity: two primary-care physical activity prescription programs. J Aging Phys Act. 2013;21(1):85.

65. Seabra AF, Mendonça DM, Thomis MA, Peters TJ, Maia JA. Associations between sport participation, demographic and socio-cultural factors in Portuguese children and adolescents. Eur J Public Health. 2008;18(1):25-30.

66. Farrell L, Shields MA. Investigating the economic and demographic determinants of sporting participation in England. J Royal Stat Soc: Ser A (Statistics in Society). 2002;165(2):335-48.

67. Caspersen, C.J., M.A. Pereira, And Curran K.M., Changes in physical activity patterns in the United States, by sex and cross-sectional age. Med Sci Sports Exerc, 2000. 32(9): p. 1601-1609.

68. Telama R, Yang X, Viikari J, Välimäki I, Wanne O, Raitakari O. Physical activity from childhood to adulthood: a 21-year tracking study. Am J Prev Med. 2005;28(3):267-73.
69. Cousins, S.O., Social support for exercise among elderly women in Canada. Health Promotion Int, 1995. 10(4): p. 273-282 10p.

70. Scheerder J, Thomis M, Vanreusel B, Lefevre J, Renson R, Eynde BV, Beunen GP. Sports participation among females from adolescence to adulthood a longitudinal study. Int Rev Sociology of Sport. 2006;41(3-4):413-30.

71. Knuth AG, Hallal PC. Temporal trends in physical activity: a systematic review. J Phys Act Health. 2009;6(5):548.

72. Stamatakis $E$, Chaudhury M. Temporal trends in adults' sports participation patterns in England between 1997 and 2006: the health survey for England. Br J Sports Med. 2008;42(11):901-8.

73. Jenkin CR, Eime R, Westerbeek HM, Uffelen V, J GZ. Why don't older adults participate in sport? Reported prepared for the Australian Sports Commission. Australia: Victoria University, Institute of Sport, Exercise and Active Living (ISEAL); 2016.

74. Fairclough SJ, Boddy LM, Hackett AF, Stratton G. Associations between children's socioeconomic status, weight status, and sex, with screen-based sedentary behaviours and sport participation. Int J Pediatr Obes. 2009;4(4): 299-305.

75. Gracia-Marco L, Tomàs C, Vicente-Rodríguez G, Jiménez-Pavón D, Rey-López JP, Ortega FB, Lanza-Saiz R, Moreno LA. Extra-curricular participation in sports and socio-demographic factors in Spanish adolescents: the AVENA study. J Sports Sci. 2010;28(13):1383-9.

76. Downward P, Rasciute $S$. Exploring the covariates of sport participation for health: an analysis of males and females in England. J Sports Sci. 2015;33(1): 67-76.

77. Casey MM, Eime RM, Payne WR, Harvey JT. Using a socioecological approach to examine participation in sport and physical activity among rural adolescent girls. Qual Health Res. 2009;19(7):881-93.

78. Eime RM, Casey MM, Harvey JT, Charity MJ, Young JA, Payne WR. Participation in modified sports programs: a longitudinal study of children's transition to club sport competition. BMC Public Health. 2015;15(1):649.

\section{Submit your next manuscript to BioMed Central and we will help you at every step:}

- We accept pre-submission inquiries

- Our selector tool helps you to find the most relevant journal

- We provide round the clock customer support

- Convenient online submission

- Thorough peer review

- Inclusion in PubMed and all major indexing services

- Maximum visibility for your research

Submit your manuscript at www.biomedcentral.com/submit
) Biomed Central 